\title{
Sobre la protección contra abusos entre empresarios. Las cláusulas abusivas y el abuso de posición de dependencia económica ${ }^{1}$
}

\author{
Santiago Andrés Contreras Delgado²
}

"(...) se sabe por experiencia eterna que todo hombre investido de autoridad
propende a abusar de ella, no deteniéndose basta que encuentra límites.

¿Quién lo diría! La misma virtud tiene necesidad de límites".

Charles Montesquieu

\section{RESUMEN}

El presente texto aborda la problemática de las asimetrías presentes en los contratos $\mathrm{B} 2 \mathrm{~B}$ y los potenciales abusos entre empresarios, desde siempre considerados como contratantes en igualdad de condiciones, dado el carácter profesional de las partes. El artículo se enfoca, por un lado, en el abuso de la situación de dependencia económica y, por el otro, en las cláusulas abusivas; dos figuras específicas que los ordenamientos pueden adoptar para la corrección de las condiciones negociales inequitativas en los contratos B2B, su explicación y abordaje normativo, con un especial análisis del caso colombiano. Identificando cuál es el estado del arte de ambas instituciones y concluyendo

1 Fecha de recepción: 29 de abril de 2020. Fecha de aceptación: 13 de mayo de 2020. Para citar el artículo: Contreras Delgado, S. (2020). "Sobre la protección contra abusos entre empresarios. Las cláusulas abusivas y el abuso de posición de dependencia económica", en Revista Con-texto, n. 53, pp. 127-151. DOI https://doi.org/10.18601/01236458.n53.07

La primera versión del presente texto fue presentada como ponencia en el XIX Concurso Nacional Estudiantil de Derecho Comercial realizado en el marco del Xxxv Congreso Nacional de Derecho Comercial de Medellín del Colegio de Abogados de Medellín (CODEAmED), llevado a cabo en septiembre de 2019. Acreedora del Segundo Puesto. La presente versión contiene incorporaciones nuevas del autor y corrección de formato.

2 Egresado en Derecho de la Universidad Externado de Colombia, en proceso de grado. Monitor investigador del Departamento de Derecho de los Negocios hasta marzo de 2020. Correo-e: sancod1@ hotmail.com 
la necesidad de seguir explorando el horizonte de posibilidades que los sistemas normativos tienen para proveer soluciones a las situaciones abusivas entre empresarios.

Palabras clave: Dependencia económica ${ }_{i}$ Cláusulas abusivas ${ }_{i}$ Contratos B2 $\mathrm{B}_{i}$ Abuso del derecho.

\section{ABSTRACT}

This text addresses the problem of asymmetries in $\mathrm{B} 2 \mathrm{~B}$ contracts and potential abuses between businessmen, who have always been considered as equal contractual parties, given their professional status. The article focuses, on one hand, on the abuse of economic dependence and, on the other hand, on abusive clauses -two specific figures that legal systems may adopt in order to correct unfair business conditions on B2B contracts-, explaining them and their normative approach, with a special analysis of the Colombian case. And finally, identifying which is the state of the art of both institutions and concluding on the necessity to continue exploring the horizon of possibilities that the normative systems have, in order to provide solutions to abusive situations between businessmen.

Keywords: Economic Dependence; Abusive Clauses; B2B Contracts; Abuse of Rights.

\section{INTRODUCCIÓN}

La protección de los empresarios débiles no ha sido un tema lo suficientemente profundizado por los sistemas jurídicos, y solo recientemente la cuestión ha captado la atención de los estudiosos del Derecho. Los contratos contemporáneos han merecido detenidos análisis debido a las posibles complicaciones de la definición clásica como encuentro de voluntades de las partes, máxime cuando las dinámicas económicas del mundo apuntan a la producción en masa y la predeterminación de las condiciones negociales.

Desde antaño, la determinación del contenido negocial por una sola parte ha sido vista -cuando menos- con cierta reserva por parte de los legisladores y jueces. Todo ello porque la experiencia indica que en múltiples contratos hay una parte débil y una parte fuerte, y una tendencia -casi instintiva- de esta para abusar de la condición de la primera ${ }^{3}$. Las inequidades contractuales por lo general suelen presentarse en los lla-

3 Al respecto, Hinestrosa, Fernando (2015). Tratado de las Obligaciones II: De las fuentes del Negocio Jurídico II, Vol. II. $1^{\circ}$ Edición. Bogotá D.C., Universidad Externado de Colombia. ISBN 9587725158 .: (...) [E]n los que el cliente no tiene oportunidades ni opciones, por lo cual el empresario, que es la parte estable y, por razones adicionales, la parte fuerte, se siente invitada a aprovechar para sí esa posición de ventaja de becho en que se encuentra frente al otro. La sensibilidad de la sociedad y del Estado se manifestó, entonces, en términos de vigilancia y prevención, como también de remedio frente a esos riesgos y realidades de excesos y abusos (subrayado propio). 
mados contratos B2C (Business-to-Consumer), en los que el carácter profesional de uno de los extremos contractuales le otorga el poder de definición de los términos negociales, cuya normatividad aplicable es la del Derecho del consumo. Por el contrario, en los contratos B2B (Business-to-Business) se presume que, dado el carácter profesional de las partes, ambas se encuentran en una posición de igualdad y de ello no se podrían derivar-en principio- abusos contractuales, pues estos negocios reflejan la autonomía de la voluntad de las partes; razón por la cual su régimen aplicable son las codificaciones civiles y comerciales de cada país, siguiendo el régimen general de las obligaciones.

Sin embargo, esta clasificación de los contratos viene experimentando matices, porque la realidad sugiere que no todas las partes involucradas en contratos B2B sean realmente profesionales en la misma posición negocial. Muchas veces una de ellas ostenta efectivamente un control de la situación y puede llegar a utilizar de manera disfuncional su poder.

Es inevitable plantearse en este punto ciertas preguntas: ¿Qué sucede si en una relación B2B hay una parte lo suficientemente poderosa como para romper el paradigma de la igualdad negocial? ¿Es necesario que se entre a regular esta clase de conductas mediante normas jurídicas? ¿Cuenta el ordenamiento con algún instrumento para modular la conducta del empresario que se encuentra en ventaja sobre el otro profesional?

Dígase desde ya que la regulación de instituciones jurídicas concebidas para proteger al empresario débil es un tema en etapa embrionaria, pero en ningún caso, novedoso. Algunos ordenamientos se han acercado tímidamente mediante la casuística, e incluso han llegado a ofrecer soluciones en determinadas situaciones. Al margen de lo anterior, la normativa colombiana es bastante incipiente en relación con las legislaciones vanguardistas de la materia. Por lo tanto, el punto de partida es la institución del abuso del Derecho, que se abordará de forma somera y se elaborarán ilaciones argumentativas al respecto.

\section{EL ABUSO DE LA POSICIÓN DE DOMINIO}

Como punto de partida, se debe tener en cuenta que la protección contra abusos entre empresas suele enmarcarse en las disposiciones del Derecho de la competencia, ora como acto desleal, ora como práctica restrictiva de la competencia.

El abuso de la posición de dominio en el mercado es una clara conducta restrictiva de la competencia. Sin embargo, en múltiples ocasiones las autoridades de libre competencia encontraron situaciones en las que el abuso no provenía de una posición de dominio en el mercado sino puramente de una relación contractual ${ }^{4}$, cuestión que

4 Al respecto, algunos afirman que esto se debe al cambio de las dinámicas económicas, como el crecimiento de las one stop shop o los category killers. Véase: Ortiz Blanco, Luis, y León Jiménez, Rosario (2003). El abuso de la situación de dependencia económica en el derecho español. Derecho de la competencia europeo y español. Curso de iniciación, Vol. IV. ISBN: 84-9772-110-1; Jara, María Elena (2016). "El abuso de posición de dominio en situación de dependencia económica y los problemas de su aplicación en 
implicaba una conducta atípica ${ }^{5}$. Este vacío se llenó finalmente con la institución del abuso de una situación de dependencia económica. Sin embargo, en aras de aclarar la categoría, se antoja menester abordar previamente otros conceptos.

\section{a. Sobre el abuso del derecho}

En términos generales, el abuso hace referencia a la utilización disfuncional de un derecho subjetivo, esto es, contra los motivos individuales o colectivos que motivan la institución de ese derecho. Valencia Zea, siguiendo los postulados de Josserand ${ }^{6}$, establece:

[L]os derechos subjetivos de los particulares, tanto en su existencia como en su ejercicio, obedecen a una orientación determinada, y de esos derechos se abusa cuando existiendo el deber de ejercerlos no se ejercen, o se ejercen en sentido opuesto a su propio destino o contenido ${ }^{7}$.

Por su parte, la Corte Suprema, en sentencia del 9 de abril de 1942 estableció que implica "un derecho legítimo y efectivo en cuyo ejercicio se ha llegado más allá de donde corresponde a su finalidad o se le ha desviado de ella"8.

Posteriormente, en sentencia del 19 de octubre de 1994, la misma Corporación hizo referencias al abuso del derecho como derivado de la buena fe, pues estableció:

(...) [L]a evidente conexión que, en el plano de las relaciones contractuales, existe entre la prohibición del abuso y la exigencia de buena fe (...), la primera no viene a ser cosa distinta de una modalidad peculiar de infracción del imperativo general de conducta que la segunda implanta ${ }^{9}$.

Según la Corporación, el abuso de un derecho propio no es más que una infracción específica del mandato general de conducta proba que la buena fe exige. Sin embargo, el abuso del derecho tiene una individualidad conceptual a pesar de ser un derivado de la buena fe. De cualquier derecho subjetivo se puede hacer una utilización disfuncional y, ergo, existe la potencialidad de abusar de ese derecho.

el ordenamiento jurídico ecuatoriano". Foro: Revista de derecho. Derecho de la competencia. n. ${ }^{\circ}$ 26. p. 5-25. Sucre, Universidad Andina de Bolivia.

5 Dado que el Derecho de la competencia implica un régimen sancionatorio, este implicaba un análisis estricto de tipicidad.

6 Rengifo García, Ernesto (2004). Del abuso del derecho al abuso de la posición dominante. $2^{\circ}$ Edición. Bogotá D.C. Universidad Externado de Colombia. ISBN: 9586168492.

7 Valencia, Arturo (1998). Derecho civil. De las obligaciones, tomo III. $9^{a}$ edición. Bogotá: Editorial Temis. p. 304.

8 Corte Suprema de Justicia, Sentencia del 9 de abril de 1942. M.P: Ricardo Hinestroza Daza.

9 Corte Suprema de Justicia, Sentencia 125 de 19 de octubre de 1994. Ref.: Exp D-3972. M.P.: Carlos Esteban Jaramillo Schloss. 


\section{b. Abuso de la posición de dominio}

La justicia arbitral se ha referido a posición dominante de la siguiente forma:

[L]a posición dominante en una relación contractual se refiere a la posibilidad que tiene una persona por razones de superioridad originadas en causas de variada índole, de dictar o fijar los contenidos contractuales en un negocio concreto y específico, independientemente de si quien detenta tal superioridad negocial posee o no posición dominante frente al mercado en general ${ }^{10}$.

Es importante establecer que la posición de dominio no configura per se una situación de abuso del derecho, sino cuando este dominio se usa de forma disfuncional. La Corte Suprema de Justicia ha establecido que

$[\mathrm{U}] \mathrm{n}$ ejemplo sin duda persuasivo de esa clase de comportamientos irregulares, lo suministra el ejercicio del llamado "poder de negociación" por parte de quien, encontrándose de hecho o por derecho en una posición dominante en el tráfico de capitales, bienes y servicios, (...) configurándose en este ámbito un supuesto claro de abuso cuando, atendidas las circunstancias particulares que rodean el caso, una posición de dominio de tal naturaleza resulta siendo aprovechada, por acción o por omisión, con detrimento del equilibrio económico de la contratación ${ }^{11}$.

En materia contractual, la sacrosanta autonomía de la voluntad viene relegándose a un segundo plano, para dar paso a un contenido cada vez más social y cooperativo de la disposición de los intereses de los individuos. Lo anterior implica que, cuando las condiciones de los contratantes generan que la capacidad o poder de negociación de una de las partes está considerablemente mermada, el Derecho, celoso del interés de esta parte débil, puede constituir límites al contenido y ejecución de los contratos. Las circunstancias ventajosas para la parte dominante pueden propiciar situaciones que impliquen actuaciones contrarias a la buena fe y a la función económico-social de los contratos. Los diferentes legisladores paulatinamente han venido adoptando el punto de vista de reconocer la asimetría de poder en los negocios jurídicos y la importancia de la preservación del concepto prístino de justicia en estos, independientemente de lo establecido en el clausulado que, se supone, es producto de la voluntad libre de las partes. El problema radica en cómo determinar que existe un abuso, porque la respuesta debe ser otorgada en cada caso concreto.

De lo anterior se colige que el derecho a la iniciativa privada también puede ser utilizado de modo disfuncional, y ello se concreta en el concepto abuso de posición de

10 Tribunal de Arbitramiento. Laudo aribtral: Punto celular contra Comunicación celular S.A. - Comcel S.A. -. Auto n. ${ }^{\circ} 7$ del 16 de junio de 2005.

11 Corte Suprema de Justicia, Sentencia 125 de 19 de octubre de 1994. Ref.: Exp D-3972. M.P.: Carlos Esteban Jaramillo Schloss. 
dominio $^{12}$, que implica de suyo una concepción de un desequilibrio entre los participantes de una relación, ya sea en las relaciones generales (en el mercado), o específicas (en los contratos), o como establece Rengifo:

Se ha señalado que el abuso de posición dominante tiene una naturaleza bifronte en la medida en que se puede expresar en relaciones jurídicas provenientes o derivadas de un negocio jurídico o se puede expresar en el mercado ${ }^{13}$.

El abuso de la posición de dominio se presenta entonces tanto en el mercado en general, como en relaciones contractuales específicas. El primero se encuentra regulado en el Derecho de la competencia, el segundo se vincula con frecuencia a las normas de protección al consumidor. Pero no debe limitarse a estas, pues la protección al empresario débil es una tendencia del Derecho contractual moderno que implica una protección al sinalagma contractual. La prohibición de los abusos contractuales no se puede fundamentar únicamente en la calidad no profesional del consumidor. Deberían ser un imperativo general en la contratación, independientemente de la calidad del contratante. Claro está que ello no implica que deba forzosamente existir una merma en las cargas de la autonomía, sobre todo predicables de los profesionales en su oficio.

\section{LA EXPLOTACIÓN DE UNA SITUACIÓN DE DEPENDENCIA ECONÓMICA}

Antes de abordar el concepto de dependencia económica, resulta útil hacer una introducción comprendiendo el contexto jurídico nacional.

En Colombia, el Estatuto del consumidor es bastante restrictivo por cuanto la calidad de los extremos contractuales es condición imprescindible para acceder a la protección establecida en dicha ley. Al tenor del numeral 3 del artículo 5, un consumidor es:

Toda persona natural o jurídica que, como destinatario final, adquiera, disfrute o utilice un determinado producto, cualquiera que sea su naturaleza para la satisfacción de una necesidad propia, privada, familiar o doméstica y empresarial cuando no esté ligada intrínsecamente a su actividad económica. Se entenderá incluido en el concepto de consumidor el de usuario (destacado propio $)^{14}$.

¿Qué sucede cuando la necesidad a satisfacer sí está ligada intrínsecamente a la actividad económica del sujeto? No se estaría hablando de un consumidor, sino un profesional del comercio que (en teoría) tiene una capacidad de negociación similar al otro extremo negocial. Por lo tanto, cualquier protección contractual que quiera

12 Véase, Rengifo García, Ernesto (2004). Del abuso del Derecho al abuso de la posición dominante. $2^{\circ}$ Edición. Bogotá D.C. Universidad Externado de Colombia. ISBN: 9586168492.

13 Véase, Rengifo Garcia, Ernesto. op. cit. p. 401.

14 Ley 1480 de 2011 - Art. 5. 
invocar es toda aquella relacionada con el ejercicio y la trasgresión de los límites de la autonomía de la voluntad (v.g. vicios del consentimiento, violación al orden público y las buenas costumbres, etc.). De manera que el asunto se puede remitir al derecho de la competencia y a las disposiciones de los códigos civil y de comercio, y finalmente, al régimen general de las obligaciones.

Pero la práctica indica que hay situaciones en las que, incluso tratándose de dos empresas en la dinámica de un contrato B2B, una de ellas se encuentra en una condición de vulnerabilidad frente a otra, y la protección contra el abuso contractual resulta inaplicable por no tratarse de un consumidor. Lo que ha llevado incluso a los estudiosos a crear una nueva categoría contractual, los denominados negocios S2C (Supplier-toCustomer $)^{15}$, que hacen referencias a contratos en esencia B2B pero que entrañan una asimetría que puede justificar la protección jurídica de una de las partes frente al peligro que supone el poder del otro contratante.

\section{a. Concepto}

La situación de dependencia es más un fenómeno económico que jurídico, tal vez por ello las legislaciones que consagran el abuso de esta situación consideraron prudente solo establecer el supuesto de hecho sin entrar a definir detalladamente el fenómeno. En todo caso, en la doctrina encontramos definiciones como la siguiente:

La situación de dependencia económica es aquella en la que se encuentran las empresas clientes o proveedoras respecto de otra, que necesariamente ostenta una situación de poder relativo de mercado. La empresa cliente o proveedora es dependiente cuando no puede prescindir de las relaciones comerciales que mantiene con la empresa con poder relativo de mercado o empresa fuerte sin que su capacidad competitiva se vea seriamente comprometida ${ }^{16}$.

O bien:

La situación de dependencia se define, con carácter general, como la relación comercial en la que una de las dos partes de la transacción, el cliente o el proveedor, no dispone de una alternativa equivalente (...) La ausencia de alternativa hace imprescindible la relación con el dominante para continuar en el mercado ${ }^{17}$.

15 Véase, por ejemplo, Roppo, Vicenzo (2011). Del contrato con el consumidor a los contratos asimétricos: perspectivas del derecho contractual europeo. (Traducción del original: María Angélica Moreno Cruz). Revista de Derecho privado. n. ${ }^{\circ} 20$, enero-junio, pp. 177-223.

16 Zabaleta Díaz, Marta (2005-2006). "El abuso de una situación de dependencia económica, ilícito antitrust o ilícito desleal". Actas de Derecho industrial y Derecho de autor. Tomo XXVI. Madrid: Ediciones Jurídicas y Sociales, p. 365.

17 Ortiz Blanco, Luis, y León Jiménez, Rosario (2003). "El abuso de la situación de dependencia económica en el Derecho español". Derecho de la competencia europeo y español. Curso de iniciación, Volumen IV. ISBN: 84-9772-110-1. 
De una cuidadosa lectura se concluye que la situación de dependencia surge de la necesidad de mantenimiento de las relaciones comerciales por parte de una empresa con otra que no tiene la misma necesidad. Y de esta situación se abusará, como se ha ilustrado suficiente, cuando la empresa fuerte haga una utilización disfuncional de sus prerrogativas en el contexto social, en especial dentro del mercado.

\section{b. Inmersión en algunos ordenamientos jurídicos}

El Derecho comparado ha venido reconociendo que no es necesario que una de las partes sea un consumidor para que una conducta reprochable de aprovechamiento de una debilidad pueda presentarse en el marco de una contratación, esto es, muy a pesar de que se trate de un llamado contrato B2B en la que intervienen 2 profesionales del comercio. Es ingenuo pensar que en todo momento la relación contractual va a guardar un perfecto equilibrio y que en ningún momento el potencial de un poder de abuso vaya a desbordar la relación sinalagmática y termine imponiendo cargas a una de las partes. Conductas que serían reprochables por el ordenamiento jurídico. Así, algunas legislaciones europeas han consagrado el abuso de la dependencia económica como conducta típica.

\section{España}

La normativa española es una de las más desarrolladas en el ámbito del Derecho de la competencia, a tal punto que tiene la Ley 3 de $1991^{[18]}$ y la ley 52 de $1999^{[19]}$.

En materia de competencia desleal, esta conducta se encuentra tipificada en el artículo 16. 2 de la Ley 3 de 1991, limitándose a prohibir la explotación de una empresa de la situación de dependencia económica en la que se encuentren sus clientes o proveedores que no dispongan de una alternativa equivalente para ejercer su actividad. Resaltando el elemento de la no existencia de una alternativa para la empresa subordinada.

En lo referente a prácticas restrictivas de la competencia, la Ley 16 de 1989 también tipificaba la conducta en su artículo $6^{[20]}$, tipificación idéntica a la de la ley de competencia desleal.

En España, la discusión estriba en determinar la naturaleza de la conducta, si encaja más bien en una práctica restrictiva de la competencia o en un acto de competencia

18 Ley 3 de 1991, de 10 de enero, de Competencia desleal. [En línea] [Fecha de consulta: 27 de abril de 2020]. Disponible en: https://www.boe.es/buscar/pdf/1991/BOE-A-1991-628-consolidado.pdf

19 Ley 52/1999, de 28 de diciembre, de reforma de la Ley 16/1989, de 17 de julio, de Defensa de la Competencia. [En línea] [Fecha de consulta: 27 de abril de 2020]. Disponible en: http://noticias. juridicas.com/base_datos/Admin/152-1999.html

20 Ley 16/1989, de 17 de julio, de Defensa de la Competencia. [En línea] [Fecha de consulta: 27 de abril de 2020]. Disponible en: http://noticias.juridicas.com/base_datos/Admin/116-1989.html 
desleal ${ }^{21}$. Incluso hay un sector de la doctrina que establece que se trata de una "cláusula general de abuso de poder contractual en las relaciones comerciales entre empresarios ${ }^{\prime 22}$. Lo cual la sitúa por fuera de las normas relativas a la competencia, y más bien es una disposición aplicable a cualquier contrato comercial, posición que consideramos más enaltecedora de la justicia.

A pesar de que la discusión tiene algún efecto práctico, después de la Ley 16 de 1989 se expidió la Ley 15 de 2007 de defensa de la competencia, en cuya parte II del preámbulo se lee:

Sin embargo, se elimina la referencia específica al abuso de dependencia económica, que ya se encuentra regulado en la Ley 3/1991, de Competencia Desleal, y puede, por tanto, incardinarse en el falseamiento de la libre competencia por actos desleales ${ }^{23}$.

En el país ibérico se encuentra zanjada la discusión y el legislador determinó que constituye un ilícito desleal y no antitrust. Aunque podría pensarse que antes de la expedición de la Ley 15, tenía la doble naturaleza.

\section{Alemania}

La legislación alemana sobre restricción de la competencia, vertida en la Gesetz gegen Wettbewerbsbescbränkungen ${ }^{24}$ (GWB), en sus secciones $\$ 19$ y $\$ 20^{[25]}$ regula estas conductas, como una tendencia a denominarlas un abuso de posición dominante, pero en condiciones relativas. La $§ 20$ establece que:

La sección (1) § 19 (1) junto con el párrafo 2 n. ${ }^{\circ} 1$ también se aplicará a las empresas y asociaciones empresariales en la medida en que las pequeñas y medianas empresas, como proveedores o compradores de un determinado tipo de bienes o servicios comerciales, dependan de ellas de tal manera que no haya posibilidades suficientes y razonables de cambio a otras empresas (poder de mercado relativo).

21 Berenguer Fuster, Luis (2006). "Otras formas de abuso de posición dominante (con especial mención al abuso de situación de dependencia económica)". El abuso de la posición de dominio. España: Marcial Pons, Ediciones Jurídicas y Sociales, pp. 415-437.

22 Zabaleta Díaz, Marta (2005-2006). "El abuso de una situación de dependencia económica, cilícito antitrust o ilícito desdeleal". Actas de Derecho industrial y Derecho de autor. Tomo XXVI. Madrid: Ediciones Jurídicas y Sociales, p. 365.

23 Ley 15 de 2007, de 3 de julio, de Defensa de la Competencia. [En línea] [Fecha de consulta: 27 de abril de 2020]. Disponible en: https://www.boe.es/buscar/pdf/2007/BOE-A-2007-12946-consolidado. pdf

24 Traducido como Ley de Restricción de Competencia (GWB).

25 Act against Restraints of Competition in the version published on 26 June 2013 (Bundesgesetzblatt (Federal Law Gazette). [En línea] [Fecha de consulta: 27 de abril de 2020]. Disponible en: https:// www.gesetze-im-internet.de/englisch_gwb/englisch_gwb.html 
La § 19 establece la cláusula de prohibición del abuso de posición de dominio, con el título Conductas probibidas a las empresas dominantes (traducción propia) Mientras que la $\S 20$ refiere más al poder de mercado relativo, del que da cuenta la explotación de la situación de dependencia económica.

Punto relevante en el ordenamiento alemán es el pronunciamiento de la Corte de apelaciones de Düsseldorf en sentencia del 18 de noviembre de 2015 en el caso EDEKA (cadena de grandes superficies). La cual resultó sancionada por un tribunal al encontrar que después de la integración con la marca Plus en el año 2008, impuso determinadas condiciones a los proveedores so pena de cortar las relaciones contractuales con ellos. La decisión se apeló y en segunda instancia se revocó la sanción porque obraron pruebas de que en realidad sí había poder de negociación de los proveedores, por lo que no se podría configurar el abuso de la dependencia económica, volviendo al supuesto de igualdad entre partes, típica de los contratos $\mathrm{B} 2 \mathrm{~B}^{26}$.

Al margen de todo lo anterior, se puede identificar que, igual que en España, la temática es abordada desde el Derecho de la competencia.

\section{En Colombia}

El desarrollo de la categoría en Colombia no encuentra asidero en ninguna norma. No obstante, es conveniente resaltar que quizás el más explícito de los referentes a la materia es una sentencia donde la Corte Constitucional abordó el caso de un pequeño fabricante de velas en el Caquetá, cuya materia prima (parafina) adquiría de TERPEL. El comerciante denunció irregularidades en el pesaje de las cantidades de parafina adquiridas, lo que implicó la apertura de una investigación contra TERPEL, que después se rehusó a seguir suministrando la materia al pequeño comerciante. La Corte determinó:

Puede prescindirse del análisis de la posición dominante de la demandada en el mercado, pero ello no será óbice para advertir que en la concreta relación económica trabada entre el actor y aquélla se dan las notas de una manifiesta dependencia económica del primero hacia la última. En efecto, la ruptura del suministro ha colocado al pequeño empresario en una situación cercana a la clausura del negocio ${ }^{27}$.

Así, se observa cómo la Corte identifica la necesidad de protección de la empresa débil en la relación, pues finalmente ordena a TERPEL suspender su conducta abusiva, dada la especial sujeción que el negocio del pequeño comerciante tiene del suministro de parafina. De esa manera, se abre paso en la jurisprudencia a tener una especial

26 Herrera Anchustegui, Ignacio (2015). Sobre el abuso de dependencia económica en la cadena alimentaria: el asunto EDEKA. (Fecha de consulta: 27 de abril de 2020). Disponible en: http://derechocompetencia. blogspot.com/2015/12/sobre-el-abuso-de-dependencia-economica.html.

27 Corte Constitucional. Sentencia del 14 de agosto de 1997. Ref.: T-375/97. M.P.: Eduardo Cifuentes Muñoz. 
consideración a las PYMES y protegerlas de las explotaciones de los grandes agentes del mercado, no obstante tratarse, stricto sensu, en un contrato B2B.

\section{c. Críticas a la figura}

Lo innovador de la figura de la explotación de la situación de dependencia viene aparejado con múltiples inconvenientes que puede entrañar la figura, en especial si no es analizada e incorporada en su debida forma en los ordenamientos. Una primera crítica a la figura está relacionada con la necesidad/utilidad de esta, debido a que se ha establecido que los ordenamientos ya cuentan con suficientes herramientas para proteger a los empresarios débiles en los contratos con instituciones, como el carácter normativo del principio de buena fe en los contratos, los vicios del consentimiento y la lesión enorme, entre otros.

Si bien es cierto que pareciera a primera vista que la voluntad del contratante débil se encuentra obnubilada por la dependencia económica que ostenta, ello no implica que se equipare a la situación de un vicio del consentimiento. Pues al ser estos vicios instituciones típicas que implican la carencia de un elemento esencial de cualquier contrato $^{28}$, son taxativas, como lo desprende la lectura del art. 1508 del Código Civil, al consagrar el error, la fuerza y el dolo. En breve, no es equiparable al error o al dolo, porque estos dos implican una falsa representación de la realidad. En la explotación de la dependencia económica el empresario débil puede tener todo el conocimiento del negocio o estar en completa ignorancia de este y eso es independiente de que se configure la explotación de la situación. Tampoco es equiparable a la fuerza porque, como se colige del artículo 1513 C.C., este vicio está ligado a actos humanos externos que condicionan la voluntad. En la explotación de la dependencia económica no existe un acto humano en específico, sino que las condiciones de la cadena de producción y distribución son las que finalmente sitúan al empresario en desventaja. Tampoco se asemeja a la conocida lesión enorme, porque dicha figura en primer lugar solo se predica de contados contratos, en bienes inmuebles y atiende solo a desequilibrios objetivos del contrato. La explotación de la dependencia económica no se supedita (o no debería supeditarse) a circunstancias puramente objetivas, sino que se debe tener en cuenta que el empresario débil no encuentra una alternativa a la contratación, independientemente de si el desequilibrio contractual es cuantificable en cierta medida, tal y como se exige para la lesión enorme ${ }^{29}$.

Otra crítica a la figura refiere a la naturaleza de esta, pues no se predica un consenso en la academia para calificar el acto abusivo como acto de competencia desleal, práctica restrictiva de la competencia, o como elemento del régimen general de las obligaciones. La postura del autor se decanta por la última alternativa, toda vez que 
la situación de dependencia económica no necesariamente implica una situación de competencia, y además es de un interés eminentemente privado. Lo anterior aunado al hecho de que esta institución busca proteger finalmente el sinalagma contractual, su naturaleza parece indicar aún más su afinidad con las disposiciones del régimen general de las obligaciones, más que con la prohibición general del comerciante de realizar actos sancionables por la autoridad concurrencial que lo vigila.

Una tercera crítica, y quizá la que más tiene cabida debido al estado embrionario de la figura, es la que se relaciona con la posibilidad de utilización disfuncional de la figura y el desconocimiento de los efectos de su configuración en un caso concreto. Así, también es posible la hipótesis en la que un comerciante celebre un contrato con otro y válidamente haya aceptado unos términos contractuales, para después, amén de sustraerse del cumplimiento de sus obligaciones, invoque la protección por vía de alegación de explotación de dependencia económica. A este respecto, la salida más razonable implicaría la definición (ora judicial, ora legislativa) de parámetros objetivos, para determinar no solo la situación de dependencia económica, sino también el abuso de esta situación, como pueden ser:

- Determinar si hay una posición dominante en el contrato.

- Observar si esta posición es causada por la ausencia de alternativas de contratación para el contratante débil.

- Aclarar si los beneficios de la negociación contractual son únicamente económicos (evento en el que sería muy sencillo determinar el desequilibrio prestacional y determinar que existe abuso). Piénsese, por ejemplo, el evento en que el beneficio o contraprestación sea un intangible, por ejemplo un valor agregado en el activo reputacional (un beneficio a su Good Will). En este nuevo escenario es probable que aparentemente haya un abuso de la situación de dependencia, porque uno de los empresarios aceptó unas condiciones contractuales económicamente desfavorables, pero que a cambio le reportan una mejoría en su reputación. Por lo que habría que determinar en primer lugar el verdadero beneficio de la operación contractual, ello mirado no solo a partir de la dimensión de la diferencia económica de las prestaciones. Posiblemente este sea el punto que más divergencias genere, pues es el más influido por caracteres subjetivos que parecen difuminar la capacidad para determinar la existencia de un abuso. Pero ello puede reducirse por ejemplo apelando a la voluntad originaria de los contratantes, o el impacto del contrato en ambas partes (si alguna reportó un beneficio irrazonablemente superior a costa del perjuicio de la otra), entre otros indicadores.

- Establecer que, razonablemente, esa persona en particular no hubiera tenido alternativa alguna diferente a la suscripción del contrato desequilibrado ${ }^{30}$.

30 Esto referido al criterio de razonabilidad estricto y real, referido al contratante particularmente considerado, y no recurriendo a estándares difusos como el buen padre de familia o el buen hombre de negocios. 
- Determinar si hubo una situación de dependencia, y si existiendo, se abusó de esta.

- Señalar si las condiciones de inequidad son plenamente conocidas por el contratante fuerte.

- Precisar cuál sería la consecuencia jurídica de dicho contrato inequitativo (p.ej. si es un tema de interpretación, resolución, nulidad, inexistencia, entre otras).

Muchos otros parámetros pueden ser establecidos para mitigar el riesgo de inseguridad jurídica que puede generar la introducción de esta figura, que ya es una realidad en algunas latitudes y su inserción en el ordenamiento nacional debe ser evaluada cautelosamente para que la regulación no resulte disfuncional.

\section{LAS CLÁUSULAS ABUSIVAS}

Otra figura de protección al empresario débil son las cláusulas abusivas. Instituciones que bien podrían parecer en ciertos casos una manifestación específica del abuso del derecho, y que comparten una misma labor (protección contra las asimetrías contractuales), pero que, observadas con detenimiento, dan cuenta de importantes diferencias sustanciales.

\section{a. Definición}

El clausulado contractual como producto de la autonomía de las partes sigue el principio pacta sunt servanda, por eso las partes deben honrar sus propias estipulaciones como regla general. Sin embargo, como se ha visto, muchas veces los poderes de disposición de intereses y los contenidos negociales requieren algún tipo de control para evitar comportamientos contrarios a Derecho. Los contratos leoninos no son de recibo en los ordenamientos jurídicos. Al respecto, Polidura Castillo establece que

Frente a esta noción tradicional del contrato (pacta sunt servanda inflexible), ha ido abriéndose espacio la aplicación de los principios de igualdad sustancial y justicia en las relaciones contractuales, como reflejo de lo cual se observan reglamentaciones y pronunciamientos cada vez más enfáticos en temas tales como cláusulas abusivas, contratos de adhesión y derechos de los consumidores, entre otros ${ }^{31}$.

Una cláusula abusiva es una estipulación contractual que revela deficiencias en el cumplimiento de su función social, pues no refleja al contrato como instrumento negocial de cooperación sino una relación de poder, y más específico aún, de dominación. De manera que se define como aquella presente en contratos de adhesión que, en contra

31 Polidura Castillo, Adriana (2016). El restablecimiento de las condiciones contractuales frente al desequilibrio económico sobrevinientre en el Derecho privado colombiano. Disponible en: https://repositorio.uniandes.edu. co/handle/1992/13771. 
de las exigencias de la buena fe, crea un desequilibrio manifiesto entre las obligaciones de las partes ${ }^{32}$.

Al margen de lo anterior, la jurisprudencia colombiana disiente parcialmente en el punto específico en que las cláusulas abusivas están presentes únicamente en contratos de adhesión. Así, la Corte Suprema dentro de sus pronunciamientos ha reconocido lo siguiente:

... aquellas cláusulas que sirven para proporcionar ventajas egoístas a costa del contratante individual (...)

En este sentido, la calificación de abusiva, leonina o vejatoria -entre otras denominaciones más enderezadas a relievar el resquebrajamiento o erosión de la justicia contractual- (...) responde, preponderantemente, al hecho de que ella socava el equilibrio prestacional que, en línea de principio, debe existir en todo contrato, en la medida en que agrava - sin contrapartida-las condiciones en que aquellos pueden solicitar del asegurador que cumpla con su obligación de "pagar el siniestro", concretamente como corolario de la acreditación de la ocurrencia o materialización del riesgo asegurado

\section{$(\ldots)$}

lo abusivo -o despótico- de este tipo de cláusulas -que pueden estar presentes en cualquier contrato y no solo en los de adbesión o negocios tipo-, se acentúa aún más si se tiene en cuenta que el asegurador las inserta dentro de las condiciones generales del contrato (...)" (enfásis propio) ${ }^{33}$.

En el caso de estudio, la Corte Suprema determinó la injusticia que subyacía en una cláusula que limitaba los medios probatorios del beneficiario en un contrato de seguro.

Ahora bien, este tipo de cláusulas censuradas en la práctica se presentan con frecuencia en las relaciones de consumo, donde el consumidor tiene un reducido (casi nulo) poder de negociación del contenido contractual. El artículo 42 del Estatuto del consumidor establece:

Son cláusulas abusivas aquellas que producen un desequilibrio injustificado en perjuicio del consumidor y las que, en las mismas condiciones, afecten el tiempo, modo o lugar en que el consumidor puede ejercer sus derechos. Para establecer la naturaleza y magnitud del desequilibrio, serán relevantes todas las condiciones particulares de la transacción particular que se analiza. Los productores y proveedores no podrán incluir cláusulas abusivas en

32 Como establece Laguado Giraldo, Carlos (2003). "Condiciones generales, cláusulas abusivas y el principio de buena fe en el contrato de seguro". Vniversitas, (105), p. 231-251. Y Arango, Maximiliano (2016). "La causa jurídica de las cláusulas abusivas". Estudios Socio-Jurídicos, 18 (1), pp. 243-266.

33 Corte Suprema de Justicia, Sentencia del 2 de febrero de 2001. Ref.: Exp: 5670. M.P.: Carlos Ignacio Jaramilllo. 
los contratos celebrados con los consumidores. En caso de ser incluidas serán ineficaces de pleno derecho (subrayado propio) $)^{34}$.

Sin embargo, y de acuerdo con lo concluido por la Corte, a pesar de que estén expresamente previstas en el Estatuto del consumidor, las cláusulas abusivas no solamente se dan en relaciones de consumo, sino que se pueden predicar de cualquier contrato. Cosa distinta es que, dada la naturaleza asimétrica de las relaciones de consumo, este tipo de cláusulas y su desarrollo doctrinario sean muy prolíficas en dicho ámbito y más aún en los contratos no negociados (de adhesión).

\section{b. La causa jurídica de las cláusulas abusivas}

Normalmente se asocia el origen de las cláusulas abusivas al concepto de abuso del derecho, y más aún, al abuso de la posición dominante en materia contractual, incluso por una utilización del sentido común al incluir en su mismo nombre el adjetivo "abusiva". No obstante, en la actualidad se discute que estas sean producto del abuso del derecho, pues uno de los requisitos del abuso del derecho es la existencia de un daño al ejecutar o abstenerse de ejecutar dicha prerrogativa, en contra de la función social de la institución. De modo que abusar implica generar un daño, y por ello se hacía referencia en el apartado del abuso del derecho que la situación de dependencia e indefensión no eran suficientes, sino que también debe haber un abuso de la posición. Las cláusulas abusivas difieren radicalmente, puesto que, de acuerdo con las normas que las proscriben, ni siquiera hay que determinar si la ejecución o no ejecución de estas genera un daño, sino que el legislador establece que se entenderán no pactadas. La justicia arbitral se refiere a ello cuando establece que "(...) En efecto, siempre será necesario distinguir la cláusula que en sí misma se considera abusiva, de la cláusula cuyas prerrogativas son ejercidas en forma abusiva" ${ }^{25}$. Es decir, no requieren que efectivamente sean aplicadas y lesionen un derecho, sino que basta con su sola previsión en el contrato para que el ordenamiento las entienda ilícitas. Así, lo reprochable de estas cláusulas no es el causar daño, sino su mera existencia.

El Estatuto del consumidor en su artículo 43 establece un listado enunciativo de cláusulas abusivas. El numeral 5, por ejemplo, se refiere a las que "... establezcan que el productor o proveedor no reintegre lo pagado si no se ejecuta en todo o en parte el objeto contratado" ${ }^{\prime \prime 6}$. Es irrelevante el hecho de que el contrato se ejecute con normalidad, pues a partir del momento en el que se pacte, esta cláusula es ineficaz, sin importar si nunca se hizo uso de ella. Mucho más lógica resulta la conclusión anterior si se toma en cuenta el hecho de que el art. 40 del Estatuto del consumidor prevé que

35 Tribunal de Arbitramiento. Laudo arbitral: Comcelulares F.M. Ltda. Vs. Comcel S.A. Bogotá D.C., diciembre 14 del 2016.

36 Ley 1480 de 2011 - Art. 43. 
"El hecho de que algunas cláusulas de un contrato hayan sido negociadas, no obsta para la aplicación de lo previsto en este capítulo"37. La conclusión es que el hecho de negociar la cláusula no subsana la ineficacia de su estipulación, ergo, la ilicitud de la cláusula no reside únicamente en la incapacidad negocial del consumidor, sino en la afección a la conmutatividad del contrato.

No obstante, el Estatuto del consumidor genera bastantes confusiones. Por ejemplo, el Título VII, sobre Protección contractual, contiene el Capítulo II, que se titula "Condiciones negociales generales y contratos de adbesión" (destacado propio) ${ }^{38}$. Por otro lado, el mencionado artículo 40 se encuentra en el Capítulo II del título VII, lo que implica que se enmarca en las condiciones generales de contratación y los contratos de adhesión (Cap. II), y dentro de la gran temática de la protección contractual (Título VII). La interpretación sistemática, de acuerdo con la ubicación del artículo 40, permite inferir de forma lógica que las condiciones generales de contratación son aplicables tanto a los contratos de adhesión como a aquellos en los que el consumidor haya negociado las condiciones (lo anterior gracias a lo dispuesto en el artículo 40), esto es, en contratos diferentes a los de adhesión ${ }^{39}$. En suma, las condiciones generales de contratación se aplican a cualquier contrato de consumo en la normativa colombiana, lo cual implica una reinterpretación de la norma, pues gran parte de la doctrina sostiene que únicamente existen en los contratos de adhesión.

Otro ejemplo de falencias en la técnica legislativa que han permitido confusiones es que el artículo 38 del Estatuto, según el cual "En los contratos de adhesión, no se podrán incluir cláusulas que permitan al productor y/o proveedor modificar unilateralmente el contrato o sustraerse de sus obligaciones ${ }^{140}$, es en realidad un artículo enunciativo de cláusulas abusivas y que no debería estar situado en el Capítulo II del título VII, sino en el Capítulo III sobre, precisamente, Cláusulas Abusivas.

Ahora bien, surge la duda de si el ya mencionado artículo 40 se limita únicamente al capítulo de condiciones generales de contratación o su extensión también puede comprender el capítulo de cláusulas abusivas. Cuestión que equivale a preguntarse si una cláusula abusiva que ha sido negociada aún conserva su ineficacia o el hecho de haber sido producto de negociaciones subsana la ilicitud de estos pactos. Esta duda no es solo de estas latitudes jurídicas; si por ejemplo se acude al Derecho Comunitario europeo, se encontrará la misma disquisición, pues la directiva 93/13/CEE establece en su artículo 3 lo siguiente:

1. Las cláusulas contractuales que no se hayan negociado individualmente se considerarán abusivas si, pese a las exigencias de la buena fe, causan en detrimento del consumidor un

39 Esta norma probablemente haga referencia a situaciones donde formal o aparentemente se invite al consumidor a negociar los términos contractuales pero que, finalmente, no tendrá participación en la determinación del contenido final del negocio. 
desequilibrio importante entre los derechos y obligaciones de las partes que se derivan del contrato.

2. Se considerará que una cláusula no se ha negociado individualmente cuando haya sido redactada previamente y el consumidor no haya podido influir sobre su contenido, en particular en el caso de los contratos de adhesión.

El becho de que ciertos elementos de una cláusula o que una cláusula aislada se bayan negociado individualmente no excluirá la aplicación del presente artículo al resto del contrato si la apreciación global lleva a la conclusión de que se trata, no obstante, de un contrato de adbesión.

El profesional que afirme que una cláusula tipo se ha negociado individualmente asumirá plenamente la carga de la prueba.

3. El Anexo de la presente Directiva contiene una lista indicativa y no exhaustiva de cláusulas que pueden ser declaradas abusivas ${ }^{41}$.

El Consejo Europeo ha entendido entonces que pueden existir contratos de adhesión en los que haya sido posible la negociación del contenido, situación cuando menos exótica, pero que se encuentra recogida en el supuesto de hecho. Lo anterior implicaría que las cláusulas abusivas también pueden predicarse de contratos negociados, conclusión a todas luces lógica si se acoge la idea de que la ineficacia de las cláusulas abusivas se da porque estas desaparecen la conmutatividad y el sinalagma negocial.

En la normativa española, se encuentra el Real Decreto Legislativo 1/2007, mediante el cual se aprueba el TRLGDCU, cuyo artículo 8 establece:

1. Se considerarán cláusulas abusivas todas aquellas estipulaciones no negociadas individualmente y todas aquellas prácticas no consentidas expresamente que, en contra de las exigencias de la buena fe causen, en perjuicio del consumidor y usuario, un desequilibrio importante de los derechos y obligaciones de las partes que se deriven del contrato.

4. No obstante lo previsto en los apartados precedentes, en todo caso son abusivas las cláusulas que, conforme a lo dispuesto en los artículos 85 a 90, ambos inclusive: a) vinculen el contrato a la voluntad del empresario; b) limiten los derechos del consumidor y usuario; c) determinen la falta de reciprocidad en el contrato; $d$ ) impongan al consumidor y usuario garantías desproporcionadas o le impongan indebidamente la carga de la prueba $a_{i}$ ) resulten

41 Directiva 93/13/CEE del Consejo, de 5 de abril de 1993, sobre las cláusulas abusivas en los contratos celebrados con consumidores. [en línea] [Fecha de consulta: 27 de abril de 2020]. Disponible en: http://civil.udg.es/epclp/texts/es/93-13.htm. 
desproporcionadas en relación con el perfeccionamiento y ejecución del contrato, o f) contravengan las reglas sobre competencia y derecho aplicable ${ }^{42}$.

El común denominador de la existencia de una lista negra de cláusulas estriba en su afectación directa a la correlatividad de obligaciones, mucho más que en el hecho de que representen un abuso del derecho. Ello, recordando, porque las cláusulas no requieren ejecutarse para que se entiendan abusivas, lo que se traduce en que no hay necesidad de la existencia de un daño para que el ordenamiento responda, restándole eficacia a las estipulaciones abusivas ${ }^{43}$.

Pues bien, una alteración abusiva de la conmutatividad entre las prestaciones de un contrato no está supeditada a una especie contractual definida; como bien se mencionó antes, es una cuestión diferente que en cierto tipo de negocios sea más frecuente. El Tribunal de Arbitramento Meg@enlace Net S.A. Vs. Telefónica Móviles Colombia S.A. estableció:

La autonomía de la voluntad privada en el campo de la contratación ha de entenderse como libertad de participar en la contratación y de establecer, así mismo, de manera libre, el contenido y alcance del negocio convenido, sin que pueda entenderse que esta libertad habilita para lograr condiciones generales vejatorias, abusivas o desleales. Las así formuladas, deben ser reprimidas, pues la libertad y los instrumentos con los cuales adquiere su mayor presencia, como el desarrollo contractual de las relaciones privadas, deben ser empleadas, de igual manera, con pulcritud y transparencia, para que en ella se origine, una buena y equilibrada ley para las partes ${ }^{44}$.

Lo anterior tiene relevancia práctica en la medida en que, si se empieza a superar la concepción de que las cláusulas abusivas son expresiones del abuso de posición dominante y más bien se empiezan a asociar a una vulneración del principio de conmutatividad del contrato (como una práctica que lesiona directamente el sinalagma negocial) ${ }^{45}$, se entiende por qué este tipo de cláusulas no se encuentran únicamente en los contratos de consumo, sino que son predicables de cualquier negocio jurídico y que se encuentran

42 Real Decreto Legislativo 1/2007, de 16 de noviembre, por el que se aprueba el texto refundido de la Ley General para la Defensa de los Consumidores y Usuarios y otras leyes complementarias. [En línea] [Fecha de consuta: 27 de abril de 2020]. Disponible en: http://noticias.juridicas.com/base_datos/ Admin/rdleg1-2007.12t2.html.

43 Arango, Maximiliano (2016). La causa jurídica de las cláusulas abusivas. Estudios Socio-Jurídicos, 18 (1), pp. $250-251$.

44 Tribunal de Arbitramiento. Laudo arbitral: Meg@enlace Net S.A. Vs. Telefónica Móviles Colombia S.A. Bogotá D.C., marzo 25 del 2009.

45 Esa es precisamente la conclusión de Arango, Maximiliano (2016). La causa jurídica de las cláusulas abusivas. Estudios Socio-Jurídicos, 18 (1), pp. 262-263. 
en diversas normas en el ordenamiento; por ejemplo, véase el ejemplo del inciso 2 del artículo 150 del Código de Comercio ${ }^{46}$.

c. La prohibición de cláusulas abusivas como mecanismo de protección al empresario débil. Caso multiniveles

Como se ha venido sosteniendo, la prohibición de ciertas estipulaciones puede ayudar a optimizar la justicia contractual y reducir el riesgo de disfuncionalidad de los negocios. Si se acepta la conclusión de la sección anterior, se sigue forzosamente que incluso en disposiciones ajenas al Derecho del consumo también se contempla la figura de las cláusulas abusivas, y que, por ende, no se requiere ostentar la calidad de consumidor para alegar la existencia e ineficacia de una de estas cláusulas. En términos más teóricos, el efecto es que se supera la concepción de que no existen tendencias abusivas en los contratos B2B, lo cual se acomoda bastante más a la realidad de los negocios. El objetivo de la presente sección no corresponde sino a la identificación de un caso específico en el ordenamiento colombiano de cómo el establecimiento de cláusulas abusivas se erige como protección de los comerciantes con una posición contractual vulnerable.

En el año 2008, en el marco de la mediática suspensión de actividades del esquema de captación de dinero de DMG y la posterior captura del empresario David Murcia Guzmán, se intensificaron esfuerzos para establecer la definición de la difusa línea entre los negocios de mercadeo en red y las estructuras de captación ilegal que siguen el esquema Ponzi. El gobierno, habiendo declarado el Estado de emergencia social en el Decreto 4333 de 2008, intervino fuertemente este tipo de negocios, pues eran un nicho de otras actividades ilícitas, como por ejemplo el lavado de activos. Posteriormente, el Congreso observó la necesidad de regular dicha actividad por el riesgo al sistema financiero que representaba y por la desprotección que existía para los vinculados como vendedores independientes, quienes eran blanco de sucesivos abusos por parte de las empresas multinivel. El anterior panorama desembocó en la presentación el Proyecto de Ley 48 de 2011, como una primera propuesta de legislación de la actividad multinivel en Colombia. El esfuerzo finalmente dio sus frutos con la expedición de la Ley 1700 del 27 de diciembre de $2013^{[47]}$.

En la exposición de motivos de la ley se lee lo siguiente:

En ese sentido, se puede decir que las actividades multinivel le ofrecen oportunidades económicas a un grupo considerable de la población que, dada sus limitaciones de disponibilidad y escasa formación, anteriormente estaba excluido del mercado. Según datos del DANE

46 Este artículo establece: "Las cláusulas del contrato que priven de toda participación en las utilidades a algunos de los socios se tendrán por no escritas, a pesar de su aceptación por parte de los socios afectados con ellas".

47 Ley 1700 de 2013. Por medio de la cual se reglamentan las actividades de comercialización en red o mercadeo multinivel en Colombia. 
respecto de los inactivos, las mujeres dedicadas a los oficios del hogar disminuyeron 7,6\% en el trimestre de julio-septiembre de 2009; las estudiantes aumentaron 1,2\%; y las mujeres dedicadas a otra actividad aumentaron $2,5 \%$, respecto al mismo trimestre del año pasado.

Para proteger a este grupo de la población de los posibles abusos de empresas que actualmente no están reguladas, es indispensable contar con este tipo de proyectos.

\section{$(\ldots)$}

Es común, sobre todo en los países latinoamericanos, que los distribuidores conozcan sobre la existencia de un contrato de distribución y sus condiciones hasta después de firmarlo; contrato que en la mayoría de las ocasiones no es público y no puede obtenerse sino por vía de un distribuidor. Así, quien se constituye como tal se suscribe en condiciones que, cuando no son equitativas, descubre tardíamente que le son imposibles de cumplir. Además, en muchos casos ya cuando está involucrado en el negocio y en su "nueva vida", encuentra que para rescindir de su contrato debe acogerse a circunstancias y condiciones poco leales e injustas frente a su compañia mentora.

En efecto, uno de los objetivos del proyecto de ley era reducir las posibilidades que las compañías multinivel tenían de abusar de los vendedores independientes, que, también de acuerdo con la exposición de motivos, en su mayoría son personas pertenecientes a grupos socioeconómicos particularmente vulnerables.

El objeto de la Ley 1700, de acuerdo con su artículo 1, "es regular el desarrollo y el ejercicio de las actividades de mercadeo denominadas multinivel incluyendo, entre otros, el mercadeo en red"48. En sus 13 artículos, la Ley 1700 se enfoca en la regulación de las actividades multinivel, definidas como aquellas que contienen 3 elementos:

- La búsqueda o la incorporación de personas naturales, para que estas a su vez incorporen a otras personas naturales, con el fin último de vender determinados bienes o servicios.

- El pago, o la obtención de compensaciones u otros beneficios de cualquier índole, por la venta de bienes y servicios a través de las personas incorporadas, y/o las ganancias a través de descuentos sobre el precio de venta.

- La coordinación, dentro de una misma red comercial, de las personas incorporadas para la respectiva actividad multinivel.

En otras palabras, el esquema de negocios multinivel consiste en que una compañía multinivel vincula una serie de vendedores independientes para comercializar un producto, y a su vez los vendedores mismos van incorporando otros vendedores independientes a cambio de comisiones y beneficios. mientras tanto la compañía coordina y suministra a los independientes los bienes y servicios para que sean comercializados. En últimas, 
la relación entre la compañía y cada uno de los vendedores implica actividades de coordinación y suministro del producto.

Ahora bien, para los propósitos del presente escrito debe hacerse especial mención al artículo 4 de la ley, el cual define al vendedor independiente como "la persona natural comerciante o persona jurídica que ejerce actividades mercantiles, y que tiene relaciones exclusivamente comerciales con las compañías descritas en el artículo $2^{\circ}$ de la presente ley ${ }^{\prime \prime 4}$.

No queda duda entonces del carácter mercantil de las personas que intervienen en el mercadeo multinivel. Por un lado, las compañías multinivel (de acuerdo con el Decreto 24/2016, reglamentario de la Ley 1700) deben ser sociedades mercantiles constituidas de conformidad con la ley colombiana, o bien sociedades extranjeras con sucursal en el territorio nacional. Por otro lado, el mencionado artículo 4 de la ley establece la calidad de comerciante del vendedor independiente. De lo anterior se colige que los contratos celebrados entre estos dos agentes se enmarcan en la categoría de contratos B2B (o incluso en los llamados S2C, de los que se habló previamente).

El artículo 5 de la normativa establece los derechos de los vendedores independientes. Se transcribe la disposición:

Artículo $5^{\circ}$. Derechos de los vendedores independientes. Además de los derechos que les confieran sus contratos y la ley, los vendedores independientes tendrán derecho a:

1. Formular preguntas, consultas y solicitudes de aclaración a las compañías multinivel, quienes deberán contestarlas de manera precisa, antes, durante y después de su vinculación con el respectivo vendedor independiente. Estas deberán versar sobre los productos o servicios vendidos, o sobre el contenido, alcance y sentido de cualquiera de las cláusulas de los contratos que los vinculen con ellas, incluyendo toda información relevante relativa a las compensaciones o recompensas u otras ventajas de cualquier índole previstas en los contratos, y sobre los objetivos concretos cuyo logro dará derecho a los correspondientes pagos.

Asimismo, sobre los plazos y fechas de pago o de entrega, cuando se trate de compensaciones en especie.

Las respuestas a las preguntas, consultas, o solicitudes de aclaración de que trata el inciso anterior del presente numeral, deberán ser remitidas a la dirección, correo electrónico u otros medios que suministren los vendedores independientes que las formulen, dentro de los plazos previstos en las normas vigentes para la respuesta a las peticiones de información.

2. Percibir oportuna e inequívocamente de las compañías multinivel las compensaciones, o ventajas a las que tengan derecho en razón a su actividad, incluyendo las que hayan quedado pendientes de pago una vez terminado el contrato entre las partes. 
3. Conocer, desde antes de su vinculación, los términos del contrato que regirá su relación con la respectiva compañía multinivel, independiente de la denominación que el mismo tenga.

4. Ser informado con precisión por parte de la compañía multinivel, de las características de los bienes y servicios promocionados, y del alcance de las garantías que correspondan a dichos bienes y servicios.

5. Mediante escrito dirigido a la compañía multinivel, terminar en cualquier tiempo, y de forma unilateral, el vínculo contractual.

6. Suscribirse como vendedor independiente de una o más compañías multinivelistas.

7. Recibir una explicación clara y precisa sobre los beneficios a que tiene derecho por la inscripción a una compañía multinivel de forma que no induzca a confusión alguna.

8. Recibir de la respectiva compañía multinivel, información suficiente y satisfactoria sobre las condiciones y la naturaleza jurídica del negocio al que se vincula con él como vendedor independiente, y sobre las obligaciones que el vendedor independiente adquiere al vincularse al negocio; al igual que sobre la forma operativa del negocio, sedes y oficinas de apoyo a las que puede acceder en desarrollo del mismo, en términos semejantes a los del numeral primero de este artículo.

9. Recibir de manera oportuna e integral en cantidad y calidad, los bienes y servicios ofrecidos por la compañía multinivel.

Parágrafo 1. Cualquier cláusula del contrato que vincule a un vendedor independiente con una compañía multinivel, en la cual se prevea la renuncia a alguno de estos derechos o a otros que se establezcan en esta ley, o que impida su ejercicio, se considerará inexistente.

Parágrafo 2. Dentro del costo inicial de participación, las compañías multinivel deberán incluir materiales de capacitación, así como referencias y guías de información en relación a cómo hacer el negocio, sobre una base no lucrativa (destacado propio) ${ }^{50}$.

Para efectos del presente trabajo, resulta particularmente relevante lo dispuesto en el Parágrafo $1^{\circ}$, ya que establece que los derechos de los vendedores independientes son irrenunciables en el contrato, y que, si un pacto así se llega a estipular, se tendrá por no escrito. Además, el parágrafo reconoce que hay ciertas cláusulas que implican una alteración a los derechos y obligaciones del contrato de forma desproporcionada, y el legislador decidió establecer la inexistencia como su consecuencia. Lo cual coincide 
con los elementos y efectos de las cláusulas abusivas, tal y como aparecen previstas también en el estatuto del consumidor. La prohibición en los términos establecidos en la Ley 1700 es absoluta, esto es, no se subsana la ilicitud de la cláusula por el hecho de haber sido negociada por parte del vendedor independiente, sino que su sola existencia, no condicionada a ninguna otra circunstancia, genera el reproche legal atribuido.

El efecto es que al hacer irrenunciables los derechos del vendedor independiente, se proscribe que aquello vaya en contra de lo dispuesto y se establece un sistema de protección frente a los abusos que las compañías multinivel tendían a establecer en los contratos. Condición agravada si se recuerda la particular vulnerabilidad de los grupos socioeconómicos que encuentran en las ventas independientes un sustento de vida. En este sentido, se puede evidenciar cómo la prohibición de las cláusulas abusivas puede erigirse como una protección en los contratos que celebran los empresarios débiles (los vendedores independientes en el presente caso) con aquellos que se encuentran en una posición negocial más cómoda (las compañías multinivel).

\section{CONCLUSIÓN}

Cada vez más se empieza a evidenciar una ingente necesidad de romper el paradigma de la igualdad entre empresarios cuando estos celebran contratos. La simple profesionalidad ya no debe ser el único parámetro que permita determinar si las partes merecen igual trato para el ordenamiento jurídico o si la tutela de alguna puede justificar la regulación de ciertos contenidos contractuales. Las leyes aún no ofrecen una solución unánime y será labor de los jueces determinar cuándo en un contrato B2B existen estipulaciones desequilibradas merecedoras de corrección. Toda vez que estas se funden en una relación inicua entre las partes, a las que el legislador y el operador judicial tradicionalmente no pondrían atención por no tratarse de relaciones de consumo. La necesidad es evidente y aunque las dos instituciones expuestas en el presente trabajo (el abuso de posición de dominio por explotación de la situación de dependencia económica y la prohibición de cláusulas abusivas) representan un genuino avance en la materia, todavía queda mucha labor teórica y práctica que permita dar solución a los (cada vez más) numerosos casos, bic sunt dracones. El campo de exploración es inmenso y el potencial del tema merece una profunda discusión; porque, al final de todo, el valor de la justicia, incluso dentro de los contratos, es un derrotero filosófico que constituye la carta de navegación de todo el sistema normativo.

\section{REFERENCIAS}

Arango, Maximiliano (2016). "La causa jurídica de las cláusulas abusivas". Estudios SocioJurídicos, 18 (1), pp. 243-266.

Berenguer Fuster, Luis (2006). "Otras formas de abuso de posición dominante (con especial mención al abuso de situación de dependencia económica)". El abuso de la posición de dominio. España: Marcial Pons, Ediciones Jurídicas y Sociales, pp. 415-437. 
Herrera AnChustegui, Ignacio (2015). Sobre el abuso de dependencia económica en la cadena alimentaria: el asunto EDEKA. (Fecha de consulta: 27 de abril de 2020). Disponible en: http://derechocompetencia.blogspot.com/2015/12/sobre-el-abuso-de-dependencia-economica-html.

Hinestrosa, Fernando (2015). Tratado de las Obligaciones II: De las fuentes del Negocio Jurídico II, Vol. II. $1^{\circ}$ Edición. Bogotá D.C., Universidad Externado de Colombia. ISBN 9587725158.

JARA, MARía Elena (2016). "El abuso de posición de dominio en situación de dependencia económica y los problemas de su aplicación en el ordenamiento jurídico ecuatoriano". Foro: Revista de derecho. Derecho de la competencia. N. ${ }^{\circ}$ 26. pp. 5-25. Sucre, Universidad Andina de Bolivia.

Laguado GiRaldo, Carlos (2003). "Condiciones generales, cláusulas abusivas y el principio de buena fe en el contrato de seguro". Vniversitas, (105), pp. 231-251.

OrTiz BlanCO, Luis y LEÓn JimÉnEZ, Rosario (2003). "El abuso de la situación de dependencia económica en el derecho español". Derecho de la competencia europeo y español. Curso de iniciación, Volumen IV. ISBN: 84-9772-110-1.

Polidura CASTILLO, Adriana (2016). El restablecimiento de las condiciones contractuales frente al desequilibrio económico sobrevinientre en el Derecho privado colombiano. Disponible en: https://repositorio. uniandes.edu.co/handle/1992/13771.

RENGifo GARCía, ERNESTO (2004). Del abuso del derecho al abuso de la posición dominante. $2^{\mathrm{a}}$ edición. Bogotá D.C. Universidad Externado de Colombia. ISBN: 9586168492.

ROPPO, ViCEnZO (2011). "Del contrato con el consumidor a los contratos asimétricos: perspectivas del derecho contractual europeo". (Traducción del original: María Angélica Moreno Cruz). Revista de Derecho privado, n. ${ }^{\circ} 20$, enero-junio, pp. 177-223.

Valencia, Arturo (1998). Derecho civil. De las olbigaciones, tomo III. $9^{a}$ edición. Bogotá: Editorial Temis. p. 304.

Zabaleta DíAZ, MARTA (2005-2006). "El abuso de una situación de dependencia económica, cilícito antitrust o ilícito desdeleal". Actas de Derecho industrial y Derecbo de autor. Tomo XXVI. Madrid: Ediciones Jurídicas y Sociales, p. 365.

\section{Sentencias}

Corte Suprema de Justicia, Sentencia del 9 de abril de 1942. M.P.: Ricardo Hinestroza Daza.

Corte Suprema de Justicia, Sentencia 125 de 19 de octubre de 1994. Ref.: Exp D-3972. M.P.: Carlos Esteban Jaramillo Schloss.

Corte Suprema de Justicia, Sentencia del 2 de febrero de 2001. Ref.: Exp: 5670. M.P.: Carlos Ignacio Jaramillo.

Corte Constitucional. Sentencia del 14 de agosto de 1997. Ref.: T-375/97. M.P.: Eduardo Cifuentes Muñoz.

\section{Tribunales de arbitramiento}

Laudo arbitral: Punto celular contra Comunicación celular S.A. - Comcel S.A. -. Auto n. ${ }^{\circ} 7$ del 16 de junio de 2005. 
Laudo arbitral: Comcelulares F.M. Ltda. Vs. Comcel S.A. Bogotá D.C., diciembre 14 del 2016.

Laudoarbitral: Meg@enlace Net S.A.Vs. Telefónica Móviles Colombia S.A. Bogotá D.C., marzo 25 del 2009.

\section{Normativa nacional}

Ley 1480 de 2011.

Ley 1700 de 2013.

Código Civil Colombiano. Art. 1502: Requisitos para obligarse, Numeral. 2.

Código Civil Colombiano. Art. 1947: Concepto de lesión enorme.

Código de Comercio, Art. 150.

\section{Normativa internacional}

Ley 3 de 1991, de 10 de enero, de Competencia desleal. [En línea] [Fecha de consulta: 27 de abril de 2020]. Disponible en: https://www.boe.es/buscar/pdf/1991/BOE-A-1991-628-consolidado.pdf.

Ley 52/1999, de 28 de diciembre, de reforma de la Ley 16/1989, de 17 de julio, de Defensa de la Competencia. [En línea] [Fecha de consulta: 27 de abril de 2020]. Disponible en: http:// noticias.juridicas.com/base_datos/Admin/152-1999.html.

Ley 16/1989, de 17 de julio, de Defensa de la Competencia. [En línea] [Fecha de consulta: 27 de abril de 2020]. Disponible en: http://noticias.juridicas.com/base_datos/Admin/116-1989. html.

Ley 15/ 2007, de 3 de julio, de Defensa de la Competencia. [En línea] [Fecha de consulta: 27 de abril de 2020]. Disponible en: https://www.boe.es/buscar/pdf/2007/BOE-A2007-12946-consolidado.pdf.

Act against Restraints of Competition in the version published on 26 June 2013 (Bundesgesetzblatt (Federal Law Gazette). [En línea] [Fecha de consulta: 27 de abril de 2020]. Disponible en: https://www.gesetze-im-internet.de/englisch_gwb/englisch_gwb.html.

Directiva 93/13/CEE del Consejo, de 5 de abril de 1993, sobre las cláusulas abusivas en los contratos celebrados con consumidores. [en línea] [Fecha de consulta: 27 de abril de 2020]. Disponible en: http://civil.udg.es/epclp/texts/es/93-13.htm.

Real Decreto Legislativo 1/2007, de 16 de noviembre, por el que se aprueba el texto refundido de la Ley General para la Defensa de los Consumidores y Usuarios y otras leyes complementarias. [En línea] [Fecha de consuta: 27 de abril de 2020]. Disponible en: http://noticias. juridicas.com/base_datos/Admin/rdleg1-2007.12t2.html. 